\title{
Matching between the Stator and Casing Treatment of a High-load Fan LIU Jun-cai ${ }^{1, a}$, YUAN Wei ${ }^{1, b}$,LIU Zhong-ze ${ }^{c}$ \\ ${ }^{1}$ National Key Laboratory of Science and Technology on Aero-Engine Aero-Thermodynamics, School of Energy and Power Engineering, Beihang University, Beijing 100191, China \\ a418771800@qq.com, byuanwei_buaa@263.net, '56727874@qq.com
}

Key words: Single-stage high-load fan; casing treatment; stator; stability extension; efficiency

\begin{abstract}
A single-stage high-load fan with arc skew slot casing treatment is chosen to examine the matching between the stator and casing treatment with arc skew slot. The numerical results show that the introduction of casing treatment with arc skew slot increases the inlet flow angle of the stator, leading to a negative angle of attack at the leading edge of the stator. Hence, properly increasing the inlet geometry angle of the stator would significantly improve the matching relationship between the casing treatment and stator, thereby enhancing the efficiency of the fan. However, increasing the inlet geometry angle of the stator excessively would increase the angle of attack on the suction surface of the stator by a large degree, leading to separation and a drop in efficiency. On the other hand, decreasing the inlet geometry angle of the stator would further increase the negative angle of attack and decrease the relative Mach number. Consequently, the flow capacity would be weakened and the efficiency loss would be increased.
\end{abstract}

\section{Introduction}

The development of turbomachinery has led to an urgent requirement to further improve the performance of fans by raising the stage pressure ratio and keeping both the efficiency and stall margin within an acceptable range[1]. For a high-load fan, its load factor and stage pressure ratio are relatively high, as is its blade tip tangential velocity, which results in greater loss of the shockwave and hampers the efficiency and aerodynamic stability[2]. Casing treatment was discovered by chance during an experiment by Koch and Smith.[34] Because casing treatment can widen the stable working range and resist distortion, it is among the most effective solutions for delaying the occurrence of rotating stall and increasing stall margin[56]. For a single rotor, casing treatment has been proven to increase the stable operating range without causing large efficiency losses. Zhang and $\mathrm{Lu}[7]$ showed that casing treatment with arc groove can increase the stall margin of a certain single rotor by $19.88 \%$ while improving the peak efficiency by $0.98 \%$. For a NASA67 rotor in particular, the introduction of casing treatment with arc skew slot can increase the stall margin by $15 \%$ and decrease efficiency by $0.6 \%[8]$

However, the introduction of casing treatment can cause large efficiency losses to multiple-stage fans and compressors. Huang et al.[9] discovered that introducing casing treatment decreased the efficiency of a single transonic fan by 3.9\%, whereas JiangChun [10] proved that casing treatment with circumferential grooves can enhance the stability margin of a single compressor by $8.10 \%$ and that of a two-stage axial-flow compressor by $8.75 \%$ but compromising on the peak efficiency by $1.88 \%$ and $3.26 \%$, respectively.

Many current studies indicate that the introduction of casing treatment can change the circulation of the fluid passage of rotors, which to some extent damages the matching between the stator and rotor and triggers a decline in efficiency in multiple-stage fans. However, so far, very little research has been conducted to attempt to discover the exact influence of this mechanism.

In this study, a single-stage high-load fan with arc skew slot casing treatment is chosen to examine the matching between the stator and casing treatment with arc skew slot. The numerical results indicate that the casing treatment with arc skew slot influences the stability enhancement 
effect of the high-load fan, and the change in matching between the stator and casing treatment is discussed with relation to how the performance of the casing treatment can be improved.

\section{Stability Improvement Effect of Casing Treatment}

\subsection{Structure of the Casing Treatment and Method of Numerical Simulation}

The structure and aerodynamic parameters of a certain single-stage transonic fan are shown in Table 1. The structure of the casing treatment and its entity picture are idemonstrated in Fig. 1, and the design parameters of the casing treatment are listed in Table 2.

Table 1 Design Parameters of a Single-stage Table 2 Design Parametters of Casing Treat-

High-load Fan ment with Arc skew slot

\begin{tabular}{ccccc}
\hline $\begin{array}{l}\text { Number of } \\
\text { blades }\end{array}$ & Diameter & $\begin{array}{l}\text { Tip-hub } \\
\text { ratio }\end{array}$ & Speed & $\begin{array}{l}\text { Tip tangential } \\
\text { velocity }\end{array}$ \\
\hline 14 & $0.46 \mathrm{~m}$ & 0.515 & $21500 \mathrm{rpm}$ & $495.32 \mathrm{~m} / \mathrm{s}$
\end{tabular}

\begin{tabular}{lcccc}
\hline $\begin{array}{l}\text { Number of s } \\
\text { lots }\end{array}$ & Slot depth & $\begin{array}{l}\text { Tangential } \\
\text { Angle }\end{array}$ & $\begin{array}{l}\text { Overlap } \\
\text { amount }\end{array}$ & $\begin{array}{l}\text { Open } \\
\text { Ratio }\end{array}$ \\
\hline 98 & $0.01 \mathrm{~m}$ & $45^{\circ}$ & $30 \%$ & 0.531
\end{tabular}

The numerical simulation applies ANSYS CFX16.0 to solve the Navier-Stokes equations. The total pressure of inlet is $101325 \mathrm{pa}$, The total temperature of inlet is $288.15 \mathrm{k}$. The direction of air inlet is axial. The computational field is shown in Fig. 2, including the treatment slot, rotor, and stator.

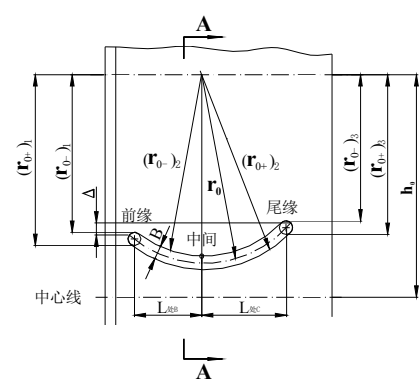

Fig. 1 Structure and Entity Picture ofCasing Treatment with Arc skew slot

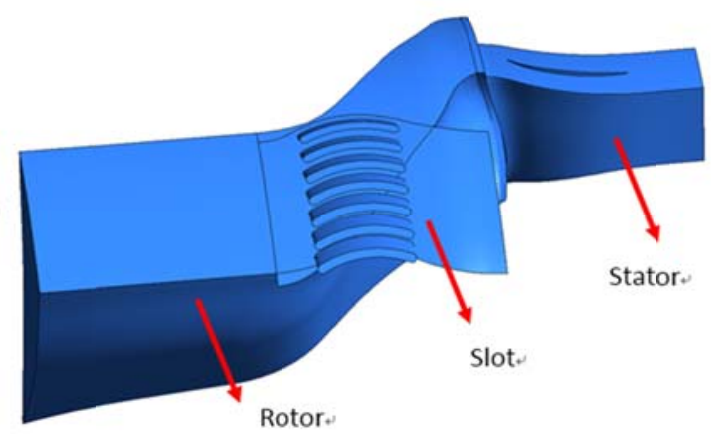

Fig. 2 Computational Field

\subsection{Results of Calculations and Analysis}

\subsubsection{Overall Characteristics}

The comparison between the case with an untreated smooth wall (marked "Basic" in Fig. 3) and that with the casing treatment (marked "Slot") for the normalized pressure ratio efficiency characteristic is shown in Fig. 3 and Table 3. In Fig. 3, under the casing treatment, the relative stable work flow range clearly increases, and the stall margin of the casing treatment in particular increases significantly from $3.265 \%$ to $12.315 \%$ in contrast to the untreated smooth wall case. Therefore, the casing treatment (slot) is an effective approach to enhance the stable operating range of the high-load fan and delay the occurrence of rotating stall. However, in terms of the relative peak efficiency, the casing treatment (slot) results in a greater efficiency loss of around $2 \%$ relative to the case with the untreated smooth wall (basic). Hence, the casing treatment resulted in a large adverse impact on the efficiency of the high-load fan.

Table 3 Characteristic Parameters of Cases with Untreated Smooth Wall and Casing Treatment

\begin{tabular}{ccccc}
\hline & Peak efficiency & Peak pressure ratio & Near stall efficiency & Near stall pressure ratio \\
\hline Basic & 1 & 0.97559 & 0.99798 & $3.265 \%$ \\
Slot & 0.98003 & 0.99233 & 0.96346 & 1 \\
\hline
\end{tabular}




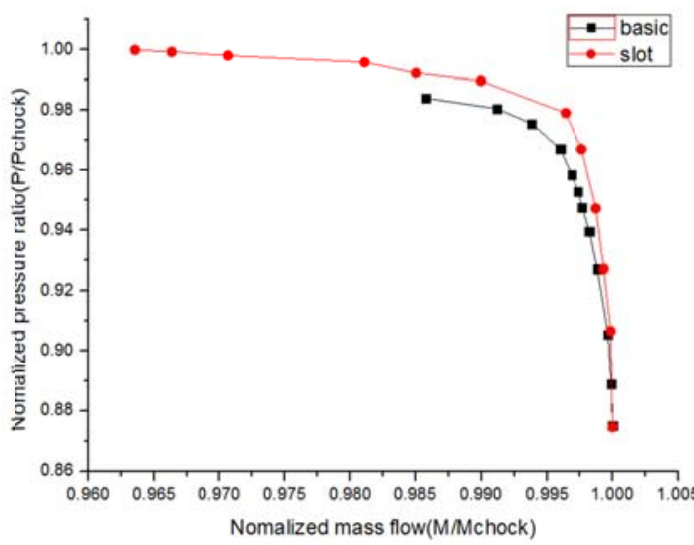

(a) Chacteristics of Pressure Ratio

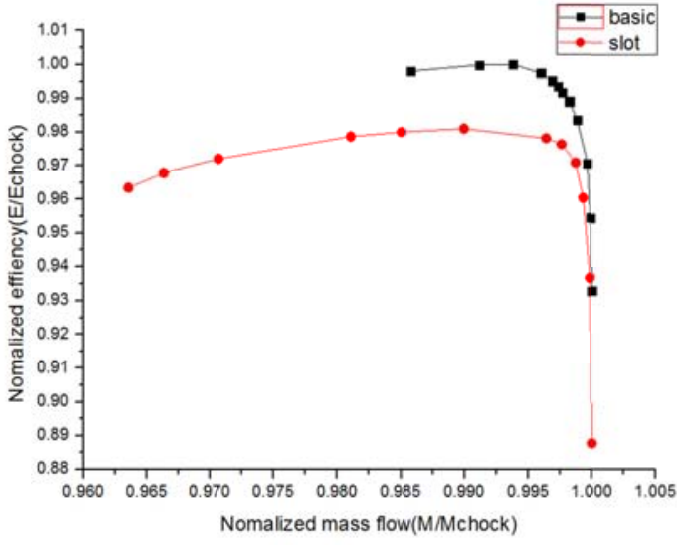

(b) Chacteristics of Efficiency

Fig. 3 Diagram of Overall Characteristic

\subsubsection{Analysis of the Stator Inlet Flow Angle}

The direction of the inlet flow angle of the stator at $90 \%$ span from the untreated smooth wall (basic) and the casing treatment (slot) is demonstrated in Fig. 4. Because the shockwave enhances the pressure, the high-pressure aftershock pumps the low energy flow and produces the jet flow in the leading edge of the rotor, thus changing the direction of circulation of the fluid in the rotor passage as well as in the inlet flow of the stator. From Fig. 4, the inlet flow angle of the stator at $90 \%$ span from the casing treatment (slot (B2)) is significantly larger than that from the untreated smooth wall (basic (B1)).

The distribution of the inlet flow angles of the stator along the span from the basic and slot cases is illustrated in Fig. 5. For span above $60 \%$, the inlet flow angle of the stator is obviously larger in the slot case than in the basic case. The change of the inlet flow angle of the stator leads to a change of the circulation of fluid in the stator passage, and the efficiency decline indicates that the matching between the stator and rotor is worsening at the present moment.

A question arises concerning how to improve the matching between the rotor and stator after being hampered by the introduction of the casing treatment and simultaneously decrease the loss of efficiency. This will be dealt with in the following section.

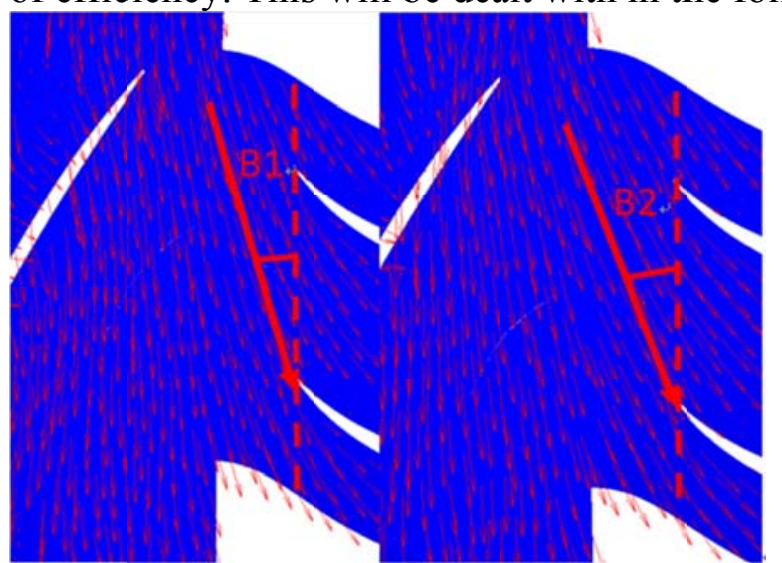

(a) Basic (b) Slot

Fig. 4 Direction of Stator Inlet Flow Angles at 90\% Spanalong the Span

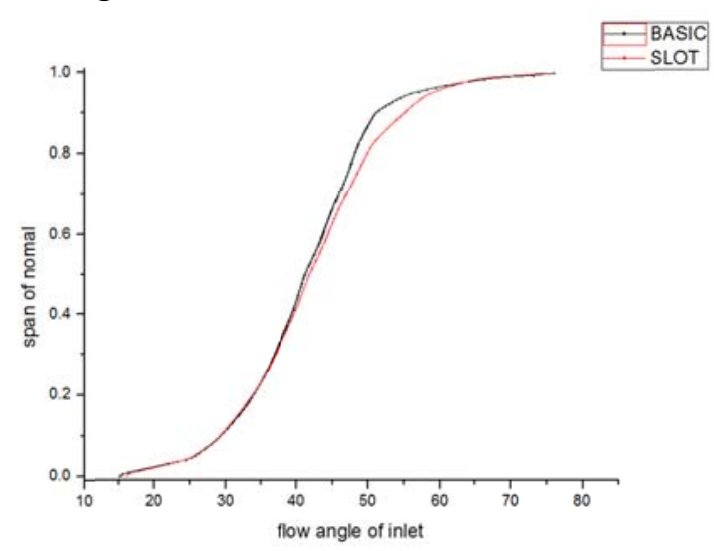

Fig. 5 Stator Inlet Flow Angle Distribution 


\section{Matching between the Stator and Casing Treatment}

\subsection{Amendment of the Stator Structure}

Previous studies have revealed that when the stacking line of the blade changes, aerodynamic parameters such as load, efficiency, and stall margin are influenced to some extent, and that the efficiency parameter is especially sensitive to the change. For the sake of convenience, in this study, an adjustable stator that is more feasible is chosen, which uses a scheme of integral adjustment to make the stator rotate for a few degrees along the stack line and change the inlet flow angle of the stator to keep the overall structure of the stator unchanged.

As shown in the previous section, after the introduction of the casing treatment, the average change of inlet flow angle of the stator is $2^{\circ}$. Thus, in this section, four different schemes are used to conduct a comparison study: (a) decrease the inlet geometry angle of the stator by $2^{\circ}$ (Reduce 2), (b) use the prototype stator (Basic), (c) increase the inlet geometry angle of the stator by $2^{\circ}$ (Enlarge_2), and (d) increase the inlet geometry angle of the stator by $4^{\circ}$ (Enlarge_4).

\subsection{Results of Calculation and Analysis}

The above four different schemes of the comparison study (Reduce_2, Basic, Enlarge_2, and Enlarge_4) are conducted for the basic and slot cases, respectively. The comparison of their pressure ratio and efficiency characteristics is illustrated in Figs. 6 and 7 and Table 4.

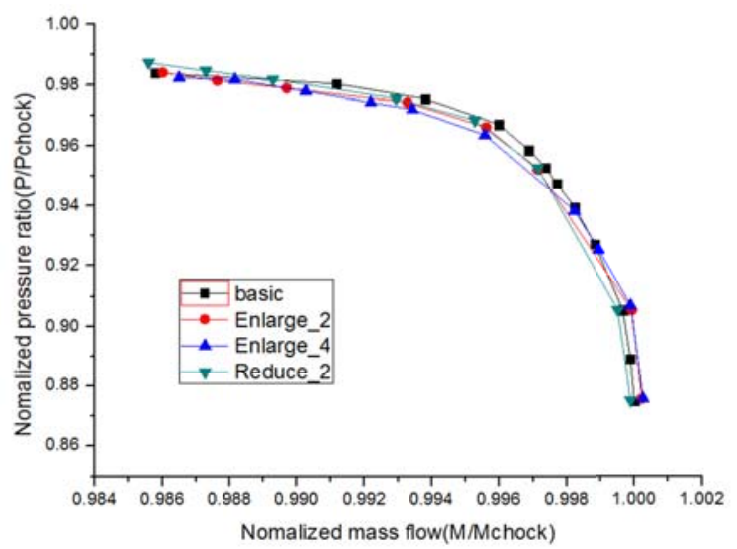

(a) Characteristics of Pressure Ratio

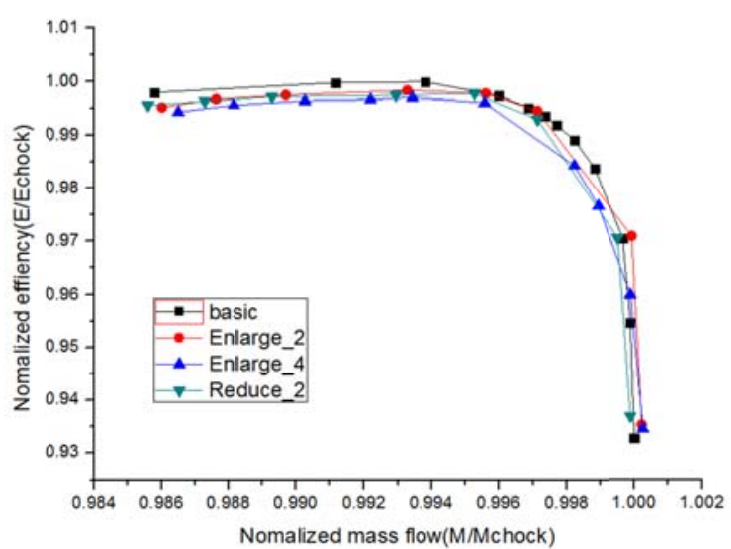

(b) Characteristics of Efficiency

Fig. 6 Overall Characteristics of Cases with Untreated Smooth Wall

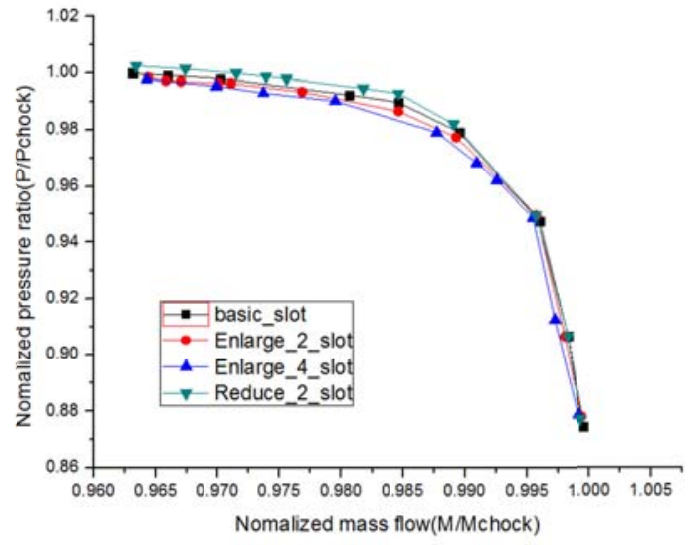

(a) Characteristics of Pressure Ratio

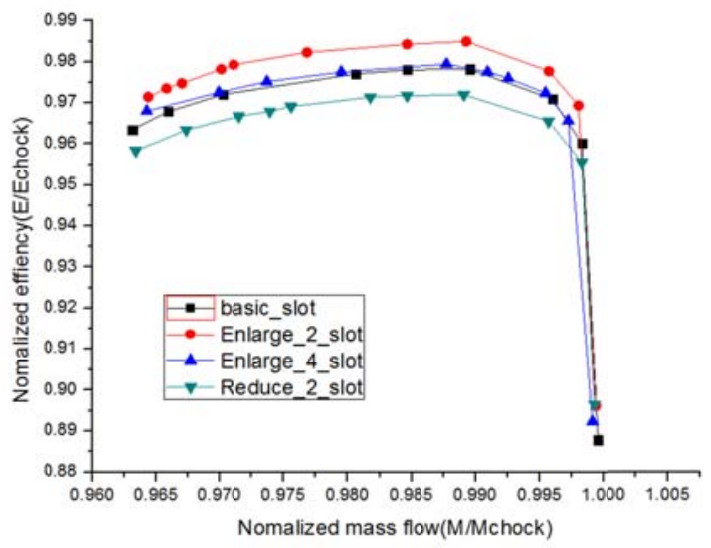

(b) Characteristics of Efficiency

Fig. 7 Overall Characteristics of Cases with Casing Treatment

The figure shows that the relative stable operating range of the casing treatment in all schemes has increased significantly, as did the operating stability margin of the fan. Thus, it is safe to conclude that the casing treatment is capable of increasing the stable operating range of the fan 
for different inlet flow angles. Moreover, for different inlet geometry angles of the stator, there is little difference in stall margin between the basic and slot cases, and their stability enhancement effects are both satisfactory.

Table 4 Characteristic Parameters of Cases with Untreated Smooth Wall and with Casing Treatment

\begin{tabular}{|c|c|c|c|c|c|c|c|c|}
\hline v & Basic & Slot & Reduce_2 & $\begin{array}{c}\text { Reduce_2 } \\
\text { slot }\end{array}$ & Enlarge_2 & $\begin{array}{c}\text { Enlarge_2 } \\
\text { slot }\end{array}$ & Enlarge_4 & $\begin{array}{c}\text { Enlarge_4 } \\
\text { slot }\end{array}$ \\
\hline Relative peak efficiency & 1 & 0.98003 & 0.99781 & 0.97197 & 0.9984 & 0.98495 & 0.99707 & 0.97941 \\
\hline Relative peak pressure ratio & 0.97559 & 0.99233 & 0.96851 & 0.98202 & 0.97435 & 0.97733 & 0.97203 & 0.97907 \\
\hline Stall margin & $3.265 \%$ & $12.395 \%$ & $3.279 \%$ & $12.472 \%$ & $3.261 \%$ & $12.364 \%$ & $3.262 \%$ & $12.372 \%$ \\
\hline
\end{tabular}

With respect to the peak efficiency for the basic case, the prototype stator reaches the highest peak efficiency, whereas its peak efficiency is reduced when the inlet geometry angle of the stator increases. Thus, it can be inferred that for the basic case, the prototype stator has an optimal matching relationship, which would worsen if the inlet geometry angle of the stator was increased.

For the slot case, the peak efficiency reaches the highest level when the inlet geometry angle of the stator is increased by $2^{\circ}$ (Enlarge_2), and it reaches the lowest level when the inlet geometry angle of the stator is decreased by $2^{\circ}$ (Reduce_2). Therefore, it can be proved that the casing treatment changes the circulation of fluid in the rotor passage, and thus increases the inlet flow angle of the stator and causes the matching between the prototype stator and rotor to deteriorate.

The above analysis reveals that by increasing the inlet geometry angle of the stator by $2^{\circ}$, the peak efficiency can reach its highest level while retaining the stability enhancement effect. In contrast, the other three changes of the inlet geometry angle of the stator result in a loss of efficiency to varying extents. The exact underlying mechanisms will be discussed in the next section.

\subsection{Flow Field Analysis}

\subsubsection{Analysis of Efficiency Distribution along the Span}

For the slot case, the efficiency distribution along the span for the rotor (a) and stage (b) is demonstrated in Fig. 8 for four different schemes with different inlet geometry angles of the stator.

With the change of inlet geometry angle of the stator, the efficiency distribution of the rotor along the span (a) remains the same. In contrast, however, for the stage (b), above $60 \%$ span, efficiency reaches its highest level when the inlet geometry angle of the stator is increased by $2^{\circ}$, and reaches its lowest level when the inlet geometry angle of the stator is decreased by $2^{\circ}$.

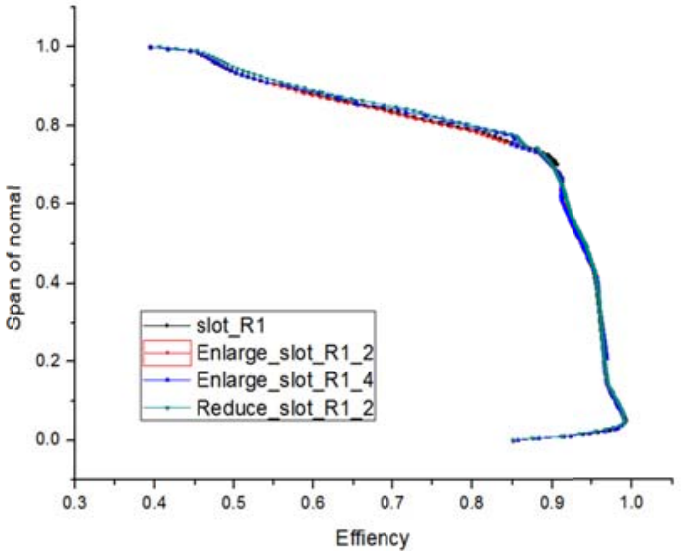

(a) Rotor

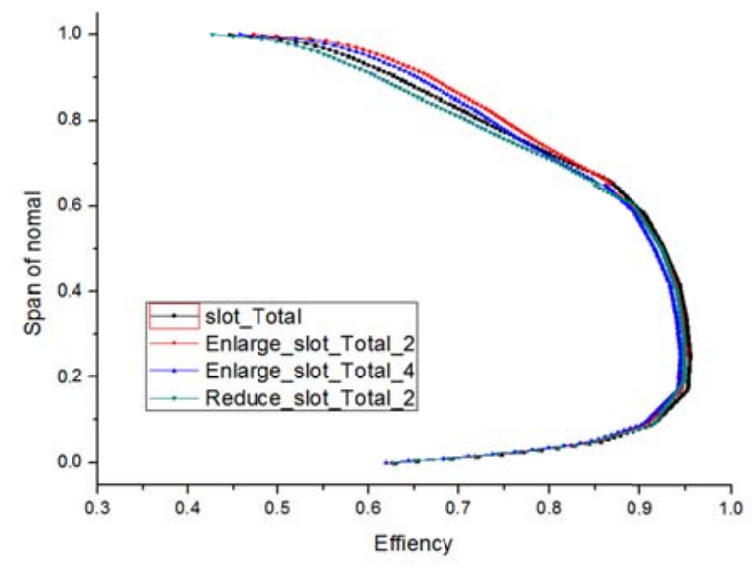

(b) Stage

Fig. 8 Efficiency Distribution along the Span 
This leads to the conclusion that the change in efficiency of the stage (b) stems from the change in efficiency loss of the stator, and that the change of the inlet geometry angle of the stator would have no impact on the rotor (a). The range of changed efficiencies for the stage (b) coincides with the range of the changed inlet geometry angles of the stator in Fig. 5, which implies that the change in efficiency loss of the stator is a direct consequence of the change of the inlet geometry angle of the stator.

The casing treatment causes the inlet flow angle of the stator to increase above $60 \%$ of the span. Increasing the inlet geometry angle of the stator by $2^{\circ}$ (Enlarge 2 ) can match the change of inlet flow angle of the stator effectively and thus improve the efficiency of the stator above $60 \%$ of the span. Decreasing the inlet geometry angle of the stator by $2^{\circ}$ (Reduce_2), on the other hand, can have the opposite effect.

\subsubsection{Flow Field Analysis of the Rotor}

For the slot case, the rotor's relative Mach number map at 99\% spans is shown in Figs. 9, respectively. For the different changes of the inlet geometry angle of the stator above, the rotor shows no significant differences in its Mach number maps for both spans. It can be inferred that the change of inlet geometry angle of the stator would not affect the flow field of the rotor and thereby have no influence on the efficiency of the rotor, which corresponds to the fact that the efficiency of the rotor does not change along the span.

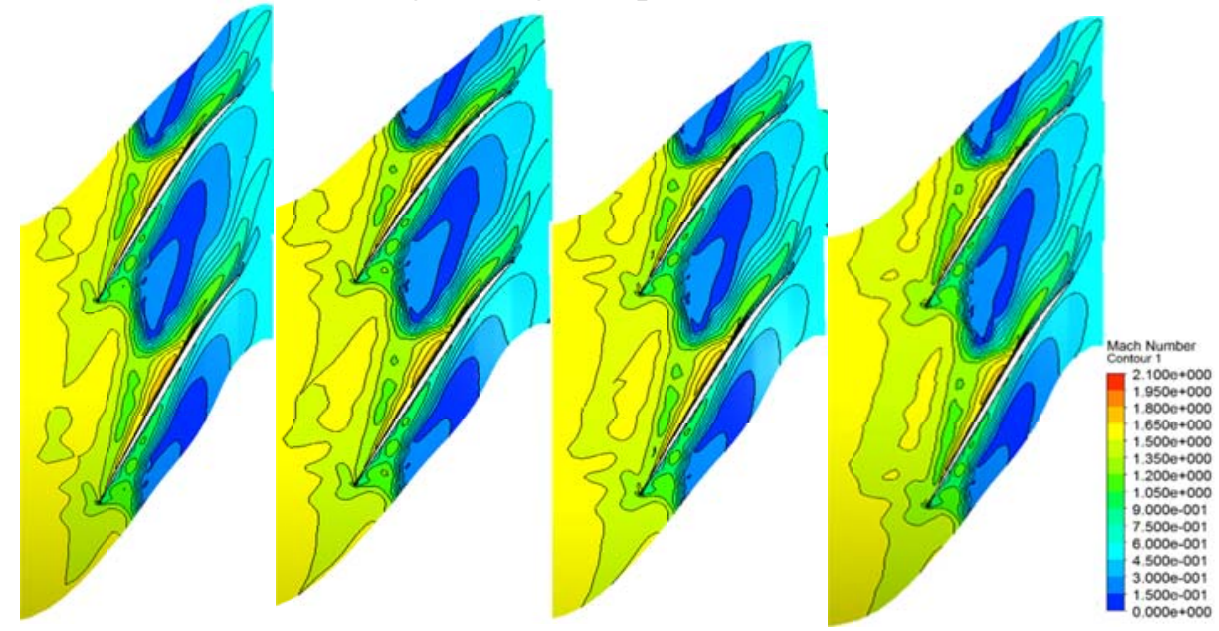

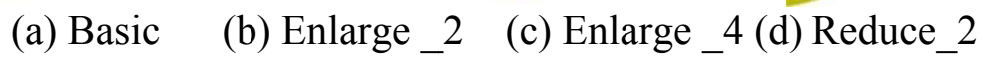

Fig. 9 Rotor's Mach Number Map at 99\% Span

\subsubsection{Flow Field Analysis of the Stator}

The angle of attack distribution along the span for both the basic and slot cases under different inlet geometry angles of the stator is shown in Fig. 10. For the slot case, the angle of attack is smaller than that for the basic case because the casing treatment increases the inlet flow angle of the stator in the upper area of the stator, thereby decreasing the angle of attack and causing the occurrence of negative angle of attack. Moreover, decreasing the inlet geometry angle of the stator by $2^{\circ}$ (Reduce_2) increases the negative angle of attack. Increasing the inlet geometry angle of the stator by $2^{\circ}$ (Enlarge_2) results in similar effects on the angle of attack as in the basic case. Increasing the inlet geometry angle of the stator by $4^{\circ}$ (Enlarge 4 ) makes the angle of attack too large, which results in the increase of the inlet geometry angle of the stator being larger than that of the inlet flow angle of the stator due to the casing treatment. 


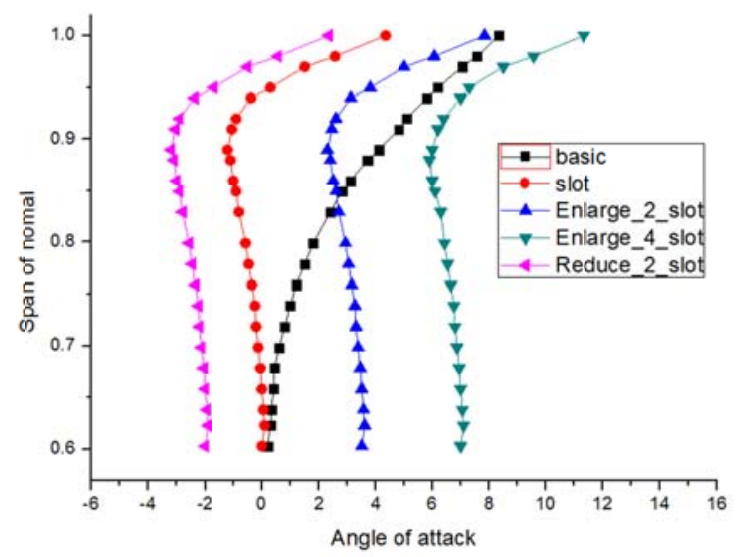

Fig. 10 Angle of Attack Distribution along the Span

\subsubsection{The Analysis of the Stator in the Flow Field}

The Mach number map of the stator at 99\% spans is demonstrated in Figs. 11, respectively. For the $99 \%$, increasing the inlet geometry angle of the stator by $2^{\circ}$ (Enlarge_2) gives the largest Mach number, whereas decreasing the inlet geometry angle of the stator by $2^{\circ}$ (Reduce_2) gives the smallest Mach number.

As shown in Figs. 11(c), increasing the inlet geometry angle of the stator by $4^{\circ}$ (Enlarge 4 ) makes the angle of attack too large, which leads to flow separation of the blade suction surface near the leading edge, and thus increases the derivation angle and the loss coefficient. Moreover, as the Mach number in Enlarge_4 is lower than that in Enlarge_2, the circulation ability of the fluid is weaker.

In Figs. 11(a), for the basic case, the stator tends to have a negative angle of attack; hence, it accelerates the flow separation from the blade pressure side, and thereby increases the loss coefficient and decreases the Mach number. For Reduce_2 (d), the negative angle of attack tends to be even larger; therefore, the Mach number is even lower and the circulation ability is even worse.

From Figs. 11(b), Enlarge 2 makes the angle of attack similar to that for the slot case, giving the largest Mach number so that the circulation ability is at its best and the efficiency loss is at its lowest.

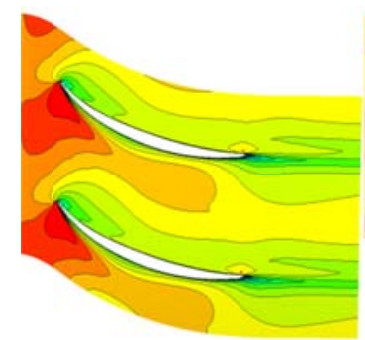

(a) Basic

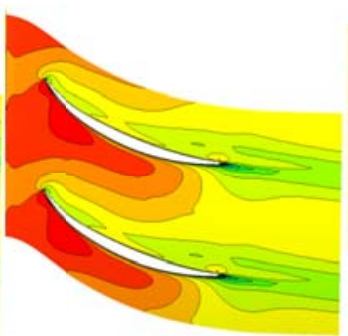

(b) Enlarge 2

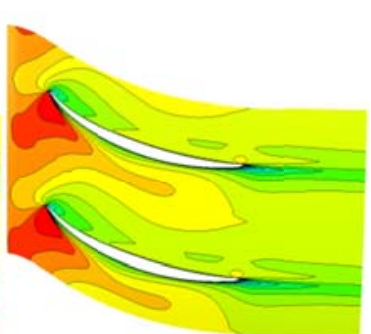

(c) Enlarge 4

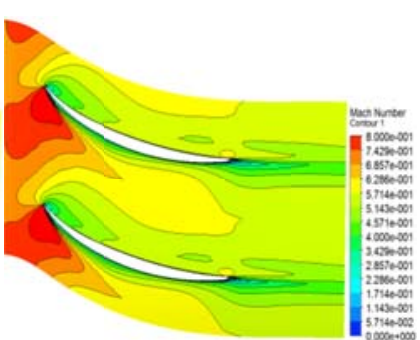

(d) Reduce_2

Fig. 11 Mach Number Map of Stator at 99\%

The entropy maps of the stator at $99 \%$ spans are shown in Figs. 12, respectively.

In the $99 \%$ spans, corresponding to the Mach number distribution in the four schemes of changing inlet geometry angles of the stator, Enlarge_2 gives the smallest entropy, whereas Reduce_2 gives the largest entropy.

With decreasing Mach number, the circulation ability of the fluid worsens, and the growing separation of fluid from the blade surface increases the loss coefficient, which in turn increases the entropy and intensifies the loss. To summarize, the change of inlet geometry angle of the stator mainly results in a change of efficiency in the middle and upper spans of the blade. 


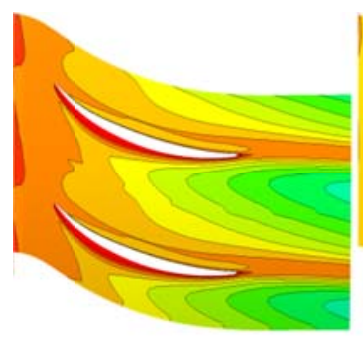

(a) Basic

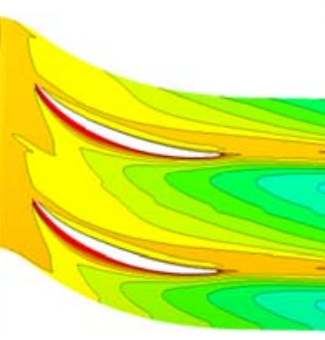

(b) Enlarge _2

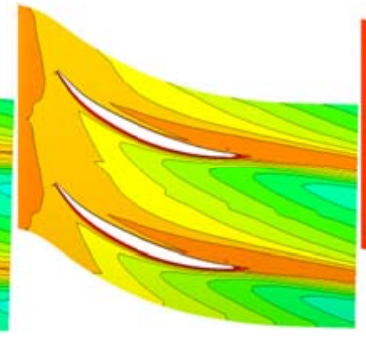

(c) Enlarge 4

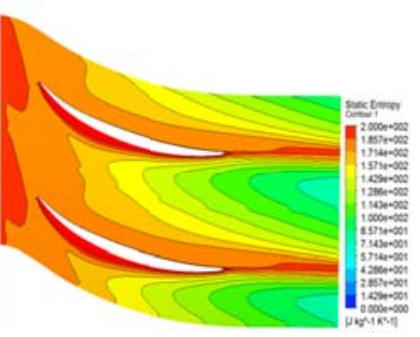

(d) Reduce 2

Fig. 12 Entropy Map of Stator at 99\% Span

\section{Conclusion}

The conclusions of the study are as follows.

(1)For a high-load fan, the casing treatment with arc skew slot has a relatively good stability increase effect and can delay the occurrence of rotating stall; however, it canmot prevent the ensuing efficiency loss. (2) For a single-stage high-load fan, the appropriate change of inlet geometry angle of the stator had no influence on the characteristics or structure of the flow field for the rotor. There are no changes in the Mach number, efficiency at different spans, or entropy for the rotor. The change of the fan stage basically stems from the change of flow field characteristics of the stator itself.

(3) When introducing the casing treatment with arc skew slot, properly increasing the inlet geometry angle of the stator can effectively decrease the efficiency loss because it can improve the angle of attack match at the inlet of the stator. Nevertheless, increasing the inlet geometry angle of the stator excessively would increase the angle of attack by a large extent. Consequently, separation of fluid from the boundary layer will occur, resulting in an increased loss of efficiency.

\section{Acknowledgement}

This investigation was supported by the Fundamental Research Funds for the Central Universities (Grant No. YWF-15-GJSYS-018).

\section{References}

[1] Wu Guo-Chuan. Development of Aeroengines [J]. Aeronautical Science \& Technology, 1997.

[2] Yuan Wei. Flow Field Analysis on the Characteristic of a High Load Compressor Fan. Journal of Propulsion Technology, 2004.

[3] Koch, C. C., Smith, L. H., Jr. Experimental Evaluation of Outer Case Blowing or Bleeding of a Single Stage Axial Flow Compressor, Part III-Performance of Blowing Insert Configuration No.1 [R]. NASA CR-54589, 1968.

[4] Koch, C. C., Smith, L. H., Jr. Experimental Evaluation of Outer Case Blowing or Bleeding of a Single Stage Axial Flow Compressor, Part VI-Final Report [R]. NASA CR-54592, 1970

[5] Lu Xingen, Chu Wuli, Zhu Junqiang. A Review of Studies on Casing Treatment of Axial-Flow Compressor. Advances in Mechanics, 2006, 36 (2): 222-232. 
[6] Kataka H. A Study on Configurations of Casing Treatment for Axial Flow Compressors, Bulletin of the JSME, 1985, 17 (230).

[7] Zhang Yan-dong, Lu Ya-jun. An Experimental Investigation on Arc Skewed Slot Casing Treatment, Journal of Aerospace Power, 1998, 13 (4).

[8] Liu Jun-Cai. Numerical Investigation of Casing Treatment for Multi-stage Transonic Compressors with Inlet Prewhirl [D]. Beijing: Beihang University, 2013.

[9] Huang, Wu Yan-hui. Impact of Different Radial Obliquity of Casing Treatment on Single Stage Transonic Fan Performance. Gas Turbine Experiment and Research, 2011, 24 (4): 1672-2620.

[10] Jiang Chun. Experimental Investigation on Effects of Grooved Treated Casings with Forward-Step on the Performance of a Two-Stage Axial-Flow Compressor [D]. Xian: NorthwesternPolytechnical University, 2001. 